\title{
PEDAGOGIA SOCIAL E JUVENTUDE EM EXCLUSÃO: COMPREENSÕES NECESSÁRIAS À FORMAÇÃO DE PROFESSORES
}

\author{
A. M. B. N. TAVARES \\ Instituto Federal de Educação, Ciência e Tecnologia do Rio Grande de Norte \\ andrezza.tavares@ifrn.edu.br
}

Artigo submetido em julho/2015 e aceito em julho/2015

DOI: $10.15628 /$ holos.2015.3220

\section{RESUMO}

O texto aborda a problemática da atuação do professor na perspectiva da Pedagogia Social. Busca-se compreender o sentido da Pedagogia Social enquanto campo de reflexões de política de formação docente e de práxis que ampliem as possibilidades da prática educativa social necessária ao protagonismo juvenil. Dentre os procedimentos metodológicos que conduziram a construção textual destacamos revisão bibliográfica e pesquisa documental, bem como, um estudo de caso desenvolvido na ocasião da construção de nossa tese de Doutorado. $O$ referido estudo de caso investigou sujeitos jovens em situação de vulnerabilidade social residentes em casas de passagens em Natal/RN e que contavam com o acolhimento e acompanhamento de educadores sociais. Como resultado as reflexões do texto revelaram que as políticas destinadas à Educação Social do jovem no Brasil, historicamente, vêm sendo dimensionadas por meio da luta dos Movimentos Sociais que reivindicam os direitos fundamentais dos excluídos; que a política voltada para a Educação Social apresenta como aspecto mais importante a relativa proteção social básica de crianças e jovens excluídos pela ótica do direito; que a política de educação social do excluído se aproxima da lógica da atenção sanitarista; que as fragilidades conceitual, metodológica, democrática e formativa necessárias às práxis dos Professores dificultam a operacionalidade de uma proposta educativa ancorada em um processo intencional possibilitador da educação emancipadora; porém, apesar das tensões, ressaltamos o valor da possibilidade da Pedagogia Social enquanto tentativa de se constituir em espaço legítimo de atuação do professor, que apesar dos obstáculos do cotidiano do trabalho e da formação, têm demonstrado sensibilidade e criatividade na mediação positiva de aprendizagens sobre consciência com a diversidade, consciência das injustiças e a possibilidade da transformação social.

PALAVRAS-CHAVE: Pedagogia Social, Educação Social, Juventude, Práxis Docente Emancipadora.

\section{UNDERSTANDING THE ASPECTS OF SOCIAL PEDAGOGY AND YOUTH EXCLUSION NECESSARY FOR TEACHERS' EDUCATION}

\begin{abstract}
The text addresses the teacher's role under the perspective of Social Pedagogy. We seek to understand the meaning of Social Pedagogy as a field of reflections regarding the teacher education policy and praxis that broaden the possibilities of the social educational practices necessary for youth protagonism. Among the methodological procedures adopted, we emphasize the bibliographic review and the documentary research, as well as a case study developed during the writing of our doctoral thesis. The case study investigated socially vulnerable young subjects residing in temporary accommodations in Natal/RN who relied on the support of social educators. The study revealed that the policies designed to Social Education of young people in Brazil have historically been dimensioned through the struggle of the Social Movements that defend the fundamental rights of excluded people; that the most
\end{abstract}

important aspect of the policy for Social Education is the relative basic social protection of children and young people excluded by the law; that the social education policy regarding excluded people approaches the logic of public health attention; that the conceptual, methodological, democratic and formative fragilities in teachers' praxis hinder the functionality of an educational proposal anchored in an intentional process that enables an emancipating education. Nevertheless, despite the tensions, we value the possibility of Social Pedagogy as an attempt to become a legitimate area of teachers' actions. In spite of the obstacles of everyday work and education, teachers have demonstrated sensitivity and creativity in the positive mediation of learnings about awareness related to diversity, consciousness related to injustices and the possibility of social transformation.

KEYWORDS: Social Pedagogy, Social Education, Youth, Emancipating Teaching Praxis. 


\section{INTRODUÇÃO}

O texto aborda a problemática da atuação do professor na perspectiva da Pedagogia Social. Busca-se compreender o sentido da Pedagogia Social enquanto campo de reflexões de política de formação docente e de práxis que ampliem as possibilidades da prática educativa social necessária ao protagonismo juvenil. Dentre os procedimentos metodológicos que conduziram a construção textual destacamos revisão bibliográfica e pesquisa documental, bem como, um estudo de caso desenvolvido na ocasião da construção de nossa tese de Doutorado.

O professor, na sociedade em que vivemos, exerce a função de educador social ao atuar em escolas, empresas, hospitais, ONG, associações, igrejas, eventos, meios de comunicação de massa, entre outros. Esses distintos panoramas de ação propõem funções para além da sala de aula. Nos dias atuais, o lema é de que onde houver uma prática educativa, se instala uma ação pedagógica. O processo de ensino-aprendizagem é vivenciado como ação que acontece no entorno de qualquer setor da sociedade, essa é grande caracterização da "sociedade do conhecimento" (GOHN, 2001). Refletir sobre a pedagogia social como alternativa para o enfrentamento da exclusão requer inicialmente pensar sobre isso.

Os cursos de licenciatura devem ao mesmo tempo formar professores, preparar pessoas capazes de compreender e colaborar para a melhoria da qualidade em que se desenvolve a educação na realidade brasileira e envolver na formação a idéia de transformação social, destacadamente no que tange a inclusão social da juventude enquanto etapa do desenvolvimento humano em que a educação pública brasileira ainda não destinou os investimentos necessários.

Sobre isso vale a pena lembrar Graciani (2006), quando afirma que os estudantes de licenciatura precisam ser formados para garantir a educação, com vistas à inclusão plena dos segmentos historicamente excluídos dos direitos sociais, culturais, econômicos e políticos. Esta concepção de formação do professor voltada para o aspecto social, sinaliza meios necessários para que os sujeitos historicamente excluídos, incluindo os jovens das periferias, reflitam criticamente sobre o contexto no qual estão inseridos e reivindiquem seus direitos como cidadãos. Nesse sentido, a educação possui um papel fundamental na constituição da sociedade e os professores se constituem em um instrumento significativo na formação e constituição destes sujeitos.

Diante das constatações assinaladas, é nosso interesse, nessa discussão, realçar as contribuições de estudos e pesquisas (FREIRE, 2003; GARCIA, 2001; IMBERNÓN, 2004; LIBANEO, 2005; NÓVOA, 1992; ROMANS, 2003; GOHN, 2006; TARDIF, 2000; SACRISTÁN, 2002) voltados para a construção de um modelo de formação do professor com vista a Pedagogia Social, à luz de propostas que levem a definir, caracterizar, analisar e associar a formação do educador social a um modelo profissional que oriente os processos formativos emancipatórios.

\section{EXCLUSÃO SOCIAL X DESENVOLVIMENTO HUMANO: POR UMA EDUCAÇÃO SOCIAL PARA ALÉM DA LÓGICA DA CONSTATAÇÃO, REPRODUÇÃO E CONFORMAÇÃO}

Eis como em tudo o forte e culpado se salva à custa do inocente e fraco (Jean-Jacques Rousseau). 
A exclusão social é um tema transversalmente contemplado em várias áreas do conhecimento. O seu sentido nem sempre é preciso, apresentando-se por meio de diversas possibilidades quanto à sua definição. O tema exclusão social corresponde a um assunto que julgamos de fundamental importância quando se objetiva discutir acerca da educação social devendo ter a devida atenção nas estruturas curriculares dos cursos de licenciatura, bem como dos diversos cenários que voltem a sua atenção para o desenvolvimento humano da juventude.

Pensar sobre exclusão social nos move a organizar o pensamento sobre as dimensões da exclusão e sobre os fatores condicionantes no sentido de conceber sugestões estratégicas de inclusão que caminhem no sentido da possibilidade da Pedagogia Social. Obviamente, não temos a pretensão de desenvolver um conceito da exclusão social, daí que não nos propomos a empreender uma discussão substantiva do tema, antes a apresentação de alguns pressupostos e proposições que, não sendo pacíficos nem consensuais, correspondem, pelo menos, aos fundamentos científicos basilares que se discutem na problematização dessa temática sociológica.

\begin{abstract}
"A exclusão social diz respeito às formas pelas quais os indivíduos podem acabar isolados, sem um envolvimento integral na sociedade mais ampla. É um conceito mais amplo do que classe baixa porque tem a vantagem de enfatizar os processos dos mecanismos de exclusão. Também é diferente da ideia de pobreza propriamente dita, concentrando sua atenção sobre uma ampla variedade de fatores que impedem que indivíduos ou grupos tenham as mesmas oportunidades que estão abertas a maioria da população (GIDDENS, 2005, p. 264).
\end{abstract}

Os fatores da exclusão social estão inevitavelmente associados às dimensões processuais em que ela se exprime. As ideias do parágrafo anterior sinalizam para a multiplicidade de fatores causais, a saber: ambientais, culturais, econômicos, políticos e sociais na origem das diversas formas de exclusão social. Do ponto de vista central desta reflexão, há que assinalar que, na origem da exclusão social, podem, portanto, estar fatores econômicos, ligados ao funcionamento do sistema, às relações internacionais, ao sistema financeiro, entre outras possibilidades.

A partir das sociedades industriais, dado o peso dominante da dimensão econômica na história da humanidade, marcante nos últimos duzentos anos, pode-se deduzir que os fatores econômicos têm tido uma importância decisiva no condicionamento das situações de exclusão social que arrolaram nessas sociedades.

Os lugares reservados aos invisíveis sociais (jovens, marginais, oprimidos, excluídos, empregáveis, miseráveis...) têm condicionado o lugar reservado à sua educação no conjunto das políticas oficiais. No Brasil, a história dessas políticas se confunde com a história do lugar social reservado aos setores populares. A educação popular, os princípios e as concepções que as inspiraram na década de 1960 continuam tão atuais em tempos de exclusão, miséria, desemprego, luta pela terra, pelo teto, pelo trabalho, pela vida.

As dispersas e diversas mobilizações populares, fortemente propagada nos anos de 1960 se prolongam por todas as últimas décadas. Diante disso, pontuamos que o ideário libertador da educação popular nascida nesse contexto, brota e rebrota persistindo na luta de contestação à exclusão e à marginalização, dado que os setores populares continuam submetidos, ao longo destas décadas. Essa ponderação nos faz supor que tais mobilizações agiram como pedagogias promotoras do ensino-aprendizagem dos direitos sociais (FREIRE, 1996). 
Neste sentido, o movimento social organizado nos mostra como a permanência das grandes questões não resolvidas questiona o progresso pessoal e social pela escolarização e pela educação nos moldes tradicionais. Esses coletivos nos lembram que ainda milhões de pessoas não saíram dos começos de sua condição humana. Como se as promessas de futuro não tivessem conseguido que a humanidade ultrapassasse seus inícios, suas necessidades primárias. Como se tudo estivesse no passado remoto, apesar de tantas promessas de futuro, de inserção e de igualdade.

Tais constatações dramáticas nos movem a repensar os contextos educativos e a formação de professores, pois é fato que não é suficiente prometer apenas um futuro para os letrados, os escolarizados, para os excluídos ou trabalhadores que sacrificam o descanso, por promessas que nem tão pouco alteram seus presentes. Os movimentos sociais denunciam que a negligência pedagógica que se tem efetivado, de sobremaneira no caso dos atendimentos dos jovens excluídos, alimenta a ideia do precário presente sem horizontes, ancorado nas vidas e nas sortes do jogo perene do presente.

O objeto das mobilizações sociais parte das necessidades localizadas no seu universo mais próximo, na reprodução mais imediata da existência, porém as reivindicações são dirigidas ampliadamente, para os governos, para as políticas públicas, para a reforma agrária, para o modelo econômico, para a igualdade, entre outras.

A ideologia emancipadora por meio da organização social gera um saber compromissado com a realidade local propondo as possibilidades de sua ampliação via o desenvolvimento. Os sujeitos construtores das premissas populares vão sendo munidos de interpretações e de referenciais para se entender como coletivo nessa "globalidade". Dessa forma deve ser entendida a educação social, como um campo de saberes que emana dos excluídos munidos de saberes, valores e estratégias desejosos do enfrentamento do sistema. As políticas de movimento social, notadamente de educação social, devem se construir como temas transversais, mais híbridos porque acolhem diversas pautas reivindicativas, aceitam e recusam as regras do sistema. Nesse espaço, o que interessa não é ganhar poder, mas veicular a participação, a autonomia e a descentralização.

Diante dos argumentos assinalados, pressupomos que reinventar a concepção mais alargada de educação social como formação e humanização plena pode ser uma das contribuições mais relevantes da pedagogia dos movimentos para a educação, destacadamente para os jovens, em que contam: o compromisso com a defesa dos direitos humanos, a construção de referenciais pedagógicos gestados na coletividade e o protagonismo dos sujeitos para os quais se dirige a ação pedagógica.

A Pedagogia Social propõe desenvolver e reconhecer a multiplicidade de estratégias de politização social, uma vez que a prática educativa está mergulhada num modo de produção que limita as possibilidades de ruptura com o sistema. Tal perspectiva pedagógica convida os sujeitos a assumirem a sua identidade coletiva, convocando os educadores sociais a tornarem a própria ação educativa objeto de luta.

A exclusão e a inclusão social devem ser analisadas em termos econômicos, sociais e políticos. Diante dessa classificação, entendemos que os fatores de exclusão social podem ser na classificação de Giddens (2005) demarcados pela natureza estrutural, de incidências conjunturais e de natureza microgenética. 
A exclusão resulta da natureza estrutural quando se relacionam com o funcionamento global das sociedades por meio do tipo de sistema econômico, de regras e imposições do sistema financeiro, de modelo de desenvolvimento, de estrutura e de características das relações econômicas internacionais, de estratégias transnacionais, de valores, de princípios sociais e ambientais dominantes, de paradigmas culturais, de condicionantes do sistema político, de atitudes e comportamentos face à natureza, modelos de comunicação e de informação, de processos de globalização etc.

Também podem resultar da natureza das incidências conjunturais, quando sua interferência é normalmente de âmbito mais local, situando-se no quadro das relações e das condições de proximidade que regulam e interferem no quotidiano dos indivíduos. Podem ter origem em áreas: de políticas autárquicas, de características do mercado local de trabalho, de modelos de funcionamento localizado dos organismos desconcentrados da administração pública, de preconceitos sociais e culturais, de normas e comportamentos locais, de estratégias de exclusão de atores locais (incluindo as associações e outras organizações), entre outros motivos.

$\mathrm{E}$, podem contemplar os fatores de natureza microgenética dos sujeitos situando-se ao nível individual e familiar. Esse nível envolve as dependências, as lacunas e as fragilidades experimentadas nos percursos pessoais, de capacidades frustradas ou não valorizadas e de incidências negativas, entre outros fatores.

Enquanto os primeiros, o estrutural e o de incidências conjunturais, referem-se às oportunidades negadas pela sociedade, o último aspecto assinala fatores de natureza microgenética, centrando-se nas capacidades e nas competências individuais e familiares não aproveitadas ou desenvolvidas. De acordo com a abordagem sócio-interacionista da psicologia da aprendizagem esse último fator apresenta elementos idiossincráticos que fazem com que o desenvolvimento psicológico seja um fenômeno único, que não ocorre da mesma maneira em dois sujeitos diferentes.

Em todos os níveis encontramos a influência dos fatores econômicos, quer entre os que estão relacionados ao funcionamento global da sociedade (sistema econômico e financeiro, modelo de desenvolvimento, relações econômicas internacionais etc), quer dentre os que atuam ao nível local (mercado local de trabalho, comportamentos e estratégias empresariais locais, políticas autárquicas com resultados de exclusão econômica etc), quer entre os que caracterizam os percursos individuais e familiares (empregos ocupados, situações de desemprego, qualificações profissionais adquiridas ou ausentes, níveis de remunerações, capacidade aquisitiva, modelos de consumo, classificação social, oportunidades de formação etc).

Diante dessas lógicas de exclusão, a literatura da área da inclusão educacional (MANTOAN, 1988) aponta provocações em um duplo sentido: destacando a necessidade de os indivíduos excluídos se tornarem cidadãos plenos e destacando a necessidade de a sociedade permitir e acolher tal cidadania. Tais direitos humanos centram-se no entendimento dialético que permite considerar a inclusão social como processos de interação entre as partes diversas de um todo.

Partindo dessas premissas, entendemos que a perspectiva da inclusão social, que de maneira geral envolve o princípio da compreensão do outro por meio da empatia, corresponde a processos que implicam em remover ou, pelo menos, minimizar os fatores sociais que condicionam a exclusão, reforçando ou maximizando as oportunidades permitidas pela sociedade, promovendo o desenvolvimento humano individual e familiar. 
A perspectiva da inclusão social se refere à vida social e educativa de todos os sujeitos, sem exceções, com relação aos direitos de acesso e de permanência às instituições sociais. No nosso entendimento, trata-se de um conceito que celebra os princípios da alteridade e da empatia, por meio da interação e da compreensão do outro, propondo viabilizar o acesso às oportunidades da sociedade, a quem dela estava excluído, permitindo a retomada da relação interativa entre o indivíduo, a família e a sociedade a que ela pertence.

Para tanto, associam-se duas lógicas, a saber: 1) a do indivíduo jovem que passa a ter acesso às oportunidades da sociedade, podendo escolher se as utiliza ou não (a este processo chamaremos de inserção na sociedade); 2 ) a da sociedade que se organiza de forma a abrir as suas oportunidades para todos, reforçando e tornando equitativas das políticas de atenção social a juventude (a este processo chamaremos de inclusão social).

A Pedagogia Social é uma perspectiva que busca a inclusão social, destacadamente na juventude, por viabilizar as seguintes lógicas: da empatia e da alteridade; das bases reflexivas e operacionais para o desenvolvimento do "ser" que assegurem saberes pessoais como a autoestima, a dignidade, o auto-reconhecimento, entre outros; das bases reflexivas e operacionais para o desenvolvimento do "estar", ou seja, saberes sociais e comunitários, tais como reativação ou criação das redes e dos laços familiares, de vizinhança e sociais mais gerais; das bases reflexivas e operacionais para o desenvolvimento do "fazer", nomeadamente saberes do trabalho profissionais: qualificações profissionais, aprendizagem de tarefas socialmente úteis, partilha de saberes-fazeres, entre outras; das bases reflexivas e operacionais para o desenvolvimento do saber "criar", o que podemos designar por capacidade de sonhar e de concretizar sonhos, assumindo riscos, protagonizando iniciativas, liderando projetos; das bases reflexivas e operacionais para o desenvolvimento do "saber", saberes informativos como escolarização, aprendizagens de saberes formais e informais, desenvolvimento de modelos de leitura da realidade e de capacidade crítica, fundamentação das decisões, entre outros; e das bases reflexivas e operacionais para o desenvolvimento do "ter", consubstanciadas no acesso ao poder de gerir, escolher e consumir (STAINBACK, 1999).

Sobre a ideia de inclusão social a sociologia da reflexividade social nos propõe o seguinte esclarecimento:

Para usufruírem de uma vida plena e ativa, os indivíduos não apenas precisam ser
visto e entendidos como excluídos, é necessário se alimentar, se vestir, se abrigar,
mas também devem ter acesso a mercadorias e serviços essenciais como
transporte, comunicação, educação... Para que haja inclusão social em uma
comunidade ou sociedade, é importante que seus membros compartilhem
escolas, serviços de saúde, transporte público, de um Estado de qualidade. Estas
instituições compartilhadas contribuem para um sentimento de solidariedade
social dentro da população (GIDDENS, 2005, p. 265).

Reconhecemos que desenvolver um processo de educação social no horizonte conceitual da inclusão social não é fácil, não se alcança com um piscar de olhos, requer planejamento, compreensão das diferenças e reflexão permanente sobre as práticas realizadas nos espaços não escolares. 
Segundo o PNUD (Programa das Nações Unidas para o Desenvolvimento) O IDH, o PIB e a renda Per Capita são formas de medir o desenvolvimento de países, regiões, estados ou municípios de acordo com os parâmetros comparativos relacionados à educação, à longevidade e à renda.

O Brasil possui, na escala econômica mundial, o lugar de nono classificado, quanto à classificação de seu Produto Interno Bruto (PIB), enquanto que no Índice de Desenvolvimento Humano (IDH), referencial para a qualidade de vida da população do país, ocupa o octogésimo primeiro lugar. Esse contraste, com relação à riqueza material e à qualidade de vida do povo, desvela uma altíssima taxa de concentração de riqueza. Por traz dessa prerrogativa, pode ser lido o comportamento das elites políticas, o quadro do uso de drogas, a prostituição, a violação contra a infância, o uso de armamentos de fogo, a miséria, a desigualdade, entre outros elementos próprios da zona de desconforto da exclusão social que afetam diretamente a juventude.

Apesar de sua ocorrência histórica, a temática da exclusão social passou a ganhar destaque no Brasil, notadamente, a partir da década de 1970, diretamente relacionada ao crescimento econômico, oriundo do período histórico dos governos da ditadura brasileira. Com a vertiginosa escalada rumo à industrialização, houve uma intensificação do padrão social excludente. O modelo econômico brasileiro favorece a concentração de capital, resultando num aumento substancial do número de pobres e de miseráveis do país.

Segundo a Unesco (2007), no Brasil, hoje, a desproporção das rendas máximas e mínimas se distanciam cada vez mais. Hoje é o país com os maiores índices de desigualdade social. Na realidade brasileira, os dez por cento (10\%) mais ricos detêm mais de quarenta e seis por cento (46\%) da renda nacional, enquanto os cinquenta por cento (50\%) mais pobres detêm somente quatorze (14\%) da renda do país. São dados, inclusive, piores dos que os apresentados por países africanos, reconhecidos mundialmente por sua situação de vulnerabilidade social.

A Constituição Federal de 1988 instituiu no Brasil um Estado Democrático de Direito (Constituição Federal, art. 1ำ, caput), o qual tem por fundamentos a soberania, a cidadania, a dignidade da pessoa humana, os valores sociais do trabalho e da livre iniciativa, bem como o pluralismo político.

A cidadania garantida pela Constituição Federal brasileira extrapola o âmbito dos direitos políticos, abarcando também os direitos sociais, ou seja, além de ser a vinculação jurídica do indivíduo a um Estado soberano, a cidadania deve compreender, ainda, uma série de direitos e exigências relativas à garantia de um mínimo existencial. Nessa sistemática, os direitos sociais já não são compreendidos como "beneficência" ou "doação gratuita estatal", mas sim incorporados como qualificadores que permitem o efetivo exercício dos direitos fundamentais e atribuem-lhes uma dimensão necessariamente social.

Percebe-se que os elevados índices de exclusão social do Brasil prejudicam o fortalecimento da democracia e de um sistema constitucional que garanta efetividade aos direitos e garantias dos cidadãos. A Constituição Brasileira reserva seu Título VIII para falar sobre os direitos sociais (educação, saúde, trabalho, moradia, lazer, segurança, previdência e assistência social). Isso porque, para a construção de um Estado Democrático, não basta garantir a um elevado número de cidadãos o direito ao voto e assegurar-lhes o exercício das garantias individuais (GADOTTI, 2000). 
É necessário ainda que se acrescente à noção de democracia a questão da distribuição equânime dos direitos sociais, pois sem condições mínimas de sobrevivência, as liberdades individuais ficam vazias e os direitos fundamentais de liberdade se transformam em privilégios para poucos. Todavia, o sistema democrático brasileiro ainda tem muito a evoluir e a realidade denuncia que as promessas da Constituição de 1988 restam por serem cumpridas.

A existência dos índices de exclusão social tão elevados demonstra que, para uma parcela considerável de brasileiros, o acesso a bens básicos de consumo não é garantido, o que atinge diretamente a dignidade dessas pessoas e lhes impede de participar ativamente da vida política e social, exercendo, assim, sua cidadania.

É preciso atribuir legitimidade ao texto constitucional, o que somente é possível ao conferirIhe maior sintonia com a realidade, atribuindo-Ihe efetividade. Enquanto parcelas consideráveis da população forem ceifadas do acesso aos direitos básicos para uma vida digna, não se poderá falar em sociedade justa ou igualitária nem na existência real de uma democracia participativa e pluralista no Brasil, com uma Constituição respeitada e de grande força normativa. Esse é, exatamente, o grande desafio atual da sociedade brasileira (GADOTTI, 2000).

A educação social deve considerar a reflexão sobre exclusão social nessa ótica dialética, enquanto processo complexo e multifacetado (polissêmico), dotado de contornos materiais, políticos, relacionais e subjetivos.

Conforme temos pontuado, historicamente, a realidade brasileira, caracterizada pela desigual distribuição de renda, produziu um contexto de marginalização e exclusão social da juventude cuja solução, necessariamente, passa pela instauração de uma nova ordem social que demanda tempo e investimentos para a área.

No Brasil, a construção da cidadania ocorre de forma inversa àquela que se dá nos países do primeiro mundo, porque as leis são autoritárias, burocráticas e inoperantes. As parcas oportunidades de cidadania surgem como resultados de processos históricos, fruto de lutas em que as leis são apenas uns de seus momentos. A mudança gradual e lenta da cultura política é fator e resultado do exercício da cidadania, sob a forma ativa, que interfere, intervém, interage e influência na construção dos processos democráticos em curso, segundo os princípios da equidade e da justiça, mas que só têm sido assegurado, via organização do movimento social, em acordo com o que já pontuamos.

A pedagogia social é um domínio de conhecimento pedagógico, de caráter teórico-prático, que se refere à socialização do sujeito, a partir da perspectiva de inadaptação social de aspectos educativos do trabalho social. Essa ideia sugere o conhecimento e a ação sobre os seres humanos, em situação de conflito ou necessidade social (MCLAREN, 2002).

A sociedade de hoje é pedagógica. Nesses tempos, a educação social deve, antes de mais nada, mediar uma aprendizagem para o "ser" e para o "conviver" em comunidade. O objetivo maior que persegue a educação social pode sintetizar-se como um contributo para que o indivíduo se associe no meio social com capacidade crítica para melhorá-lo e transformá-lo (ORTEGA, 1999).

A pedagogia social encoraja os grupos marginalizados e as comunidades marginalizadas a construir alianças políticas umas com as outras e, dessa forma, erradicar a homogeneidade cultural, interpretando e reconstruindo sua própria história. Como parte de um esforço planejado de luta anticapitalista, a pedagogia 
social procura estabelecer a igualdade social e econômica em contraste com a ideologia conservadora e liberal de oportunidade igual, que mascara a distribuição desigual existente de poder e de riqueza (MCLAREN, 2002, p.106).

O significado científico, disciplinar e intervencionista da Pedagogia Social apresenta conceitos diversificados, acumulados no tempo em função dos contextos em que se tem desenvolvido, tal como ocorre com a formação de professores na perspectiva ampliada. Portanto, torna-se necessário conhecer o processo epistemológico do pensamento sobre a Pedagogia Social para se estabelecer diálogos e fronteiras com a formação de professores comprometida com a formação emancipadora da juventude excluída.

\section{PEDAGOGIA SOCIAL: ACEPÇÃO, DIMENSÃO HISTÓRICA E PERSPECTIVAS}

Poder é toda chance, seja ela qual for, de impor a própria vontade numa relação social, mesmo contra a relutância dos outros (Max Weber).

A pedagogia social é um domínio de conhecimento pedagógico, de caráter teórico-prático, que se refere à socialização do sujeito, a partir da perspectiva de inadaptação social de aspectos educativos do trabalho social. Essa ideia sugere o conhecimento e a ação sobre os seres humanos, em situação de conflito ou necessidade social (MCLAREN, 2002).

O fortalecimento do debate da educação social tem se dado pela interlocução desenvolvida com a Pedagogia Social, como teoria e como prática de intervenção educativa, que tem impulsionado a oferta de uma formação acadêmica específica, concomitante com a consolidação do campo de atuação profissional.

A compreensão da construção histórica da Pedagogia Social considera a conceitualização, os paradigmas e as áreas de intervenção socioeducativa, propiciando referencial para se compreender as perspectivas atuais,

A construção histórica do repertório da pedagogia social está consagrada por meio de diferentes autores e correntes de pensamento. As produções teóricas de autores como Gohn (1999), Petrus (1997), Silva (2006) Simson (2001), Machado (2002), Graciani (1997,2006), Caliman (2006) têm procurado trazer estas discussões para a Educação, contextualizando historicamente a origem da Educação não-formal, da Pedagogia Social e suas implicações nas formações dos educadores (ORTEGA, 1999, p. 23).

A Pedagogia Social historicamente vem sendo construída nas questões sociais assumidas por filósofos, sociólogos e educadores, como Platão, Marx e Pestalozzi, desde o mundo clássico até a metade do século XIX. Ainda que a perspectiva assumida tenha sido humanitária, filosófica e política, esses pensadores podem ser considerados precursores da Pedagogia Social.

Comenius foi o primeiro educador a formular uma concepção pedagógico-social de caráter místico-humanitário, e Pestalozzi é apontado como o fundador da educação autônoma, rompendo com a subordinação à teologia e, consequentemente, à igreja, nas atividades educativas, características na idade média (LUZURIAGA,1993). Podemos citar Platão, Hegel, Kant, Pestalozzi, Rousseau e Paulo Freire como pensadores pioneiros dessa pedagogia. Apesar dos interesses pessoais desses estudiosos não demarcarem uma nova construção pedagógica em si, composta de 
corpo científico próprio, seus contributos filosófico heterogêneos servem, porém, de base para o posterior desenvolvimento da pedagogia social (PÉREZ, 2003).

No estudo da tradição da "Pedagogia Social" percebemos que a expressão parece ter sido usada pela primeira vez por Diesterweg no seu livro "Bibliografia para a Formação dos Professores Alemães" (1850). Esse termo foi utilizado sem nenhuma intenção epistemológica, apenas para contextualizar um determinado gênero de bibliografia pedagógica. Foi também esse autor quem primeiro utilizou a expressão "Educação Social", ainda que não tenha voltado a repeti-la em nenhum dos seus escritos. Naquele cenário o Diesterweg promoveu o uso das expressões (educação social e pedagogia social) de maneira casual e anedótica, pois, em 1850, não se conjecturava o valor atual que tais temáticas possuiriam, em virtude dos condicionantes de exclusão social.

O período em que surgiu a Pedagogia Social na Alemanha torna-se referencial para a área. Coincide com o crescimento e a consolidação das Ciências Sociais, com a racionalização e análise objetiva da vida social. Reflete os efeitos das Revoluções Industrial e Francesa, com o reconhecimento dos movimentos populares.

Com a ascensão de Hitler ao poder político e militar alemão, e a consequente censura nacional para o socialismo, os trabalhos da Pedagogia Social alemã foram interrompidos por falta de apoio estatal e por opressão às iniciativas que persistiram. Os principais autores alemães a tratarem da temática foram: Paul Natorp, filósofo neokantiano que escreveu a primeira obra que sistematiza a Pedagogia Social, publicada em 1898, intitulada "Pedagogia Social: a Teoria da educação e da vontade sobre a base da comunidade". Natorp, em 1913, restaurou os debates da Pedagogia, voltando o olhar para o indivíduo excluído dos aspectos sociais da educação. Defende, como um dos conceitos básicos, a comunidade, contrapondo-se ao individualismo, que considera origem e causa dos conflitos sociopolíticos da Alemanha.

Um segundo autor precursor dos estudos da Pedagogia Social é Krieck (1932). Para esse teórico, a formação política dos indivíduos deve estar associada à construção de valores na medida em que defendem o nacional socialismo. Propôs uma Pedagogia na sua manifestação social.

O terceiro contribuidor do debate é Nohl. Para ele, a Pedagogia Social não se refere a toda a Pedagogia, mas à parte relacionada à educação popular, apresenta, além da posição idealista de Natorp e a nacionalista de Krieck, as direções: naturalista, influenciado por Bergemann, que publicou, em 1900, a "Pedagogia Social sobre base científico-experimental", obra embasada na Antropologia e Biologia; historicista, representada por Willman e Barth, que destacam a importância da pedagogia se ocupar das ações e fenômenos coletivos, superando a restrição a ações individuais, ampliando a investigação da educação à totalidade dos processos sociais; e a sociológica, representada por Durkheim, Mannheim, Smith e Peters, que enfatizam, em diversas obras, as relações entre Sociologia e Educação. Dessas direções, a de maior repercussão foi a sociológica, que propicia, inclusive, que, num período, a Pedagogia Social fosse compreendida como Sociologia da Educação (LUZURIAGA, 1993).

Para Petrus (1998), a educação social define-se, não apenas pelas funções sociais que historicamente têm sido da sua competência, mas também por aquelas que, em resposta às necessidades derivadas do Estado de bem-estar providente, tornam-se exemplo de necessidade para o desenvolvimento humano. 
A Pedagogia Social na América Latina tem ganhado repercussão nos últimos anos. Porém, em alguns países como México, Argentina, Chile e Venezuela, apesar de ser regulamentada como profissão, ainda é pouco conhecida enquanto abordagem teórica e qualificação profissional regular. O Uruguai é, dentre os países citados, o que mais tem avançado nessa área ao lado do Brasil.

O principal referencial da Pedagogia Social na América Latina é a abordagem teórica desenvolvida por Paulo Freire para a educação de adultos, na década de 1960. A pedagogia de Freire difundiu-se como um repertório pedagógico "não autoritário", focado no oprimido que tem, como objetivo central, a "conscientização" como condição para a transformação social, implicações políticas que transcendem a educação escolar (TORRES, 1992). Pode-se afirmar que Paulo Freire é o representante nacional da Pedagogia Social e que sua obra é reconhecida internacionalmente nesta perspectiva.

Ao longo dos vinte anos de educação social na América Latina, em relação à atenção social, verifica-se o envolvimento de projetos educacionais nas seguintes abrangências, segundo Garcia (2001): 1) programas relativos a populações indígenas, nativas, referentes a questões de língua, multiculturalismo, identidade étnica, resistência à assimilação da cultura dominante; 2) programas de pesquisa participativa em ação de resgate à cultura e ao conhecimento popular para reapropriação do poder de grupos dominantes (de informação, de ideologia), apoiados na coerção e na força; 3) programas de participação comunitária, de identificação de programas educacionais, envolvendo pais, professores e alunos; 4) programas de educação popular relacionados a questões da terra, reforma agrária e educação rural; 5) programas de formação política por meio de recursos e atividades educacionais (alfabetização e necessidades de classes marginalizadas) para organização e mobilização na contestação de estruturas sociais e o poder do Estado.

Diante da pesquisa desenvolvida, temos convicção de que a matriz teórico-prática da "pedagogia social" parece estar alicerçada nas inúmeras experiências de educação popular latinoamericanas, principalmente, ocorridas nas décadas de 1960 e 1970. No entanto, na medida em que estão voltadas para mudanças objetivas no campo social, essas propostas também vão sofrendo alterações ao longo do tempo. Assim, postulamos que pensar a Pedagogia Social como um campo de conhecimentos transversais às práticas de educação não-escolar faz-se necessário para apresentar as diversas formas através das quais o fenômeno da Pedagogia Social e/ou Educação Social tem sido experimentado.

Pedagogia Social é, portanto, a indicação epistemológica que favorece a práxis transformadora para o excluído no sentido de: educar para o mundo, educar para a vida, educar para as relações, educar para as dificuldades, educar para as mudanças, educar para as transformações (reflexividades sociológicas), educar para os sonhos, educar para o discernimento, educar para o pensar, educar para as descobertas (reflexividades filosóficas), educar para o tempo (reflexividade histórica), educar para as diversidades (reflexividade antropológica), para uma sociedade mais justa, mais pedagógica e mais social (reflexividade política).

Sobre a influência do conceito de reflexividade como elemento compósito da Pedagogia Social, julgamos pertinente o seguinte pensamento:

O ator social é um indivíduo que essencialmente elabora reflexividades resultantes da sociabilidade propiciada por sua atuação. Em diferentes níveis de direções, há uma contínua circulação de sentidos entre o processo de 
individualização, a medição dos papéis sociais e o fenômeno da sociabilidade, esse movimento passa por várias concepções e sensibilidades que impulsionam essa dinâmica (FERREIRA, 2009, p. 39)

Pensar o sujeito como indivíduo reflexivo significa acreditar no processo de ressocialização, incluindo novas formações e referências culturais. É reconhecer a maleabilidade do formato biográfico, a superação da rigidez dos papéis e a atuação que o sujeito pode assumir para se adaptar às mudanças na vida social. Significa valorizar os sentidos e os significados da vida dos atores sociais e assegurar o reconhecimento de que as identidades não são obrigatórias. Elas podem ser construídas e reconstruídas (FERREIRA, 2009)!

Assim, têm sido considerados, como objetos da Pedagogia Social, dois campos distintos: o primeiro referente à socialização do indivíduo, socialização compreendida como ciência pedagógica da educação social do indivíduo, que pode ser desenvolvida pela experiência biográfica no sentido de um significativo status na sociedade, das diretrizes culturais enquanto valores que guiam o indivíduo, a autoimagem como sentimento por si mesmo e referência para os outros, a habilidade de criar e desempenhar papeis, e os estados emocionais em que cada um exprime suas intenções e sustenta as suas interações (FERREIRA, 2009, p. 40); o segundo relacionado ao trabalho social, com enfoque pedagógico, direcionado ao atendimento das necessidades humanas e sociais, desenvolvido por equipe multidisciplinar da qual participa o Educador Social, como profissional da Pedagogia Social.

Esse profissional é definido, por dois âmbitos: pelo social, em função de seu trabalho; e pelo caráter interventivo de sua ação, cuja demarcação teórica persiste controvertida devido a ideologias, filosofia e visão antropológica (ROMANS, 2003).

O Educador Social atua no campo de intervenção socioeducativa que envolve múltiplas facetas. Torna-se evidente o caráter interdisciplinar do trabalho social em ação. É a partir da integração em equipe, incluindo profissionais de diferentes áreas, que se viabilizam planos, programas, projetos de implementação, acompanhamento e avaliação nessa área.

A Pedagogia Social, como uma das áreas no campo de Trabalho Social, envolve uma série de especialidades que, na classificação de Quintana (1993), são as seguintes: 01- atenção à infância com problemas (ambiente familiar desestruturado, abandono...); 02- atenção à adolescência (orientação pessoal e profissional, tempo livre, férias...); 03- atenção à juventude (política de juventude, associacionismo, voluntariado, atividades, emprego...); 04- atenção à família em suas necessidades existenciais (famílias desestruturadas, adoção, separações...); 05- atenção à terceira idade; 06- atenção aos deficientes físicos, sensoriais e psíquicos; 07- pedagogia hospitalar; 08prevenção e tratamento das toxicomanias e do alcoolismo; 09- prevenção da delinquência juvenil. (reeducação dos dissocializados); 10- atenção a grupos marginalizados (imigrantes, minorias étnicas, presos e ex-presidiários); 11- promoção da condição social da mulher; 12- educação de adultos; 13- animação sociocultural.

Nestas considerações, destacam-se as relações sociais nas quais os homens se constituem como sujeitos sociais e históricos e a Pedagogia Social como mediadora deste processo.

Caliman, a respeito da Pedagogia Social, revela que se trata de uma ciência em construção, voltada para as classes populares. Todavia, também argumenta a necessidade de estudos mais aprofundados sobre as práticas que estão sendo realizadas nesta área: 
(...) diz respeito à diferença entre Pedagogia Escolar e Pedagogia Social. A primeira tem toda uma história e é amplamente desenvolvida pela didática, ciência ensinada nas universidades. A segunda, a Pedagogia Social, se desenvolve dentro de instituições não formais de educação. É uma disciplina mais recente que a anterior. Nasce e se desenvolve de modo particular no século XIX como resposta às exigências da educação de crianças e adolescentes (mas também de adultos) que vivem em condições de marginalidade, de pobreza, de dificuldades na área social. No Brasil atual a Pedagogia Social vive um momento de fertilidade. É um momento de criatividade pedagógica mais que de sistematização dos conteúdos e dos métodos. Ao mesmo tempo nos damos conta de que é chegado o momento no qual precisamos sistematizar toda essa gama de conhecimentos pedagógicos para compreender melhor e interpretar a realidade e projetar intervenções educativas efetivas (CALIMAN 2006, p.5).

Concordamos com o autor quando descreve que os sujeitos envolvidos na Pedagogia Social têm produzido formas e estratégias criativas de atuação. Entretanto, também consideramos que são necessários estudos mais aprofundados nesta área, pois, mesmo em uma área social, também existem projetos que apresentam características assistencialistas e não emancipatórias, estando, muitas vezes, a causa dessa deformação pedagógica na ignorância sobre o referencial relevante para se adotar.

\section{CONSIDERAÇÕES FINAIS}

O horizonte da Pedagogia Social, não se pode separar "prática de teoria, autoridade de liberdade, ignorância de saber, respeito entre educador e educando, ensinar de aprender" (FREIRE, 2003, p.106-107). A coerência da Pedagogia social para a formação da juventude ancora-se no comprometimento existencial, no qual nasce a autêntica solidariedade entre educador e educandos, pois ninguém pode se contentar com uma maneira neutra de estar e interpretar o mundo. Educar, por essência, é uma forma de intervenção no mundo, uma tomada de posição, uma decisão, por vezes, até uma ruptura com o passado e o presente. Quando fala em "educação como intervenção", Freire refere-se a mudanças reais nos diversos campos da sociedade "seja da economia, das relações humanas, da propriedade, do direito ao trabalho, à terra, à educação, à saúde, etc" (FREIRE, 2003, p.123).

A educação deve ser concebida de maneira assertiva, para que se possa estabelecer a autêntica comunicação da aprendizagem social, entre gente, com alma, sentimentos, emoções, desejos e sonhos. Essa pedagogia social é "fundada na ética, no respeito à dignidade e à própria autonomia do educando" (FREIRE, 2003, p.11) e é "vigilante contra todas as práticas de desumanização" (FREIRE, 2003, p.12). Propõe que "o saber-fazer da auto-reflexão crítica e o saberser da sabedoria exercitada ajudem a evitar a degradação humana diante do discurso fatalista da globalização (FREIRE, 2003, p.12).

Paulo Freire, o maior representante da Pedagogia social no Brasil significa muito mais que do que ensinar, é uma missão que exige comprovados saberes no seu processo dinâmico de promoção da autonomia do ser de todos os educandos na medida em que reivindica uma educação que respeita todos os atores envolvidos no processo, destacadamente os mais desfavorecidos, e liberta o pensamento das tradições desumanizantes e opressoras. 
Ao propor uma prática educativa que corroborasse com a Pedagogia Social no atendimento do excluído, sinalizou para os seguintes aspectos metodológicos: rigorosidade metódica, pesquisa, ética, estética, competência profissional, respeito pelos saberes do educando, reconhecimento da identidade cultural, rejeição de toda e qualquer forma de discriminação, reflexão crítica da prática pedagógica, corporeificação do exemplo, saber dialogar e escutar, querer bem aos educandos, ter alegria, ter esperança, ter liberdade, ter autoridade, ter curiosidade, ter a consciência do inacabamento do ser. Esses elementos podem ser compreendidos como os princípios basilares de uma prática educativa que transforma educadores e educandos e lhes garante o direito à autonomia pessoal na construção de uma sociedade cidadã que a todos respeita e dignifica, inclusive nos espaços educativos não escolares (FREIRE, 2003).

Tal concepção pedagógica não invizibiliza as injustiças que acontecem com os "esfarrapados do mundo". Ao contrário, está ao lado deles. Esse referencial sempre recomenda postura crítica frente a qualquer atitude. Tal postura é o que caracteriza a "curiosidade epistemológica" e permite que, uma vez identificados os erros, sejam feitas mudanças, as quais conduzem à melhoria das condições humanas de cada um. Sugere que se leve discussões políticas para $o$ ato educativo.

O respeito à autonomia e à dignidade de cada um é o imperativo ético que se advoga nessa pedagogia. O educador que desrespeita a curiosidade do educando, o seu gosto estético, a sua inquietude, a sua linguagem, mais precisamente, a sua sintaxe, a sua prosódia, que ironiza, que minimiza, que combate o mais tênue sinal de rebeldia legítima; tanto quanto o educador que se exime do cumprimento de seu dever, de propor limites à liberdade do aluno, que se furta ao dever de ensinar, de estar respeitosamente presente à experiência formadora do educando, transgride os princípios fundamentalmente éticos da Educação Social (FREIRE, 2003, p. 66).

A grande contribuição da Pedagogia Social para a juventude é o significado do ato de educar. Essa ação significa o envolvimento em todo o processo de troca entre educador e educando, em que ambos aprendem, ambos adquirem e provocam dúvidas, e assim, ambos crescem como seres humanos.

A Pedgogia Social propõe que o espaço de trabalho educacional deve ser transformado em arena de luta para educandos, trabalhadores e trabalhadoras, para que possam aprender como se tornar sujeitos políticos; cooperar uns com os outros, agir coletivamente achando soluções para os problemas dentro de suas comunidades; organizar e mobilizar-se em movimentos políticos unificados na luta para construir uma democracia socialista. Acredita na forte condição humana do agir politicamente. Isso significa posicionar-se contra a política capitalista hegemônica que busca caricaturar o ser humano na sua grande maioria em "bandido", "jovens e meninos de rua", "prostitutas", “doentes", "drogados", “sem teto", "sem terra” (FREIRE, 2003).

\section{REFERÊNCIAS BIBLIOGRÁFICAS}

1. FERREIRA, Adir Luiz. Havia uma sociologia na escola. Brasília: Líber, 2009.

2. FERREIRA, Adir Luiz. Formação social do sujeito contemporâneo: discutindo a socialização e os papéis sociais na vida escolar. A escola socializadora além do currículo Tradicional. Porto Alegre: Sulina, 2009.

3. FREIRE, P. Pedagogia da Autonomia: saberes necessários à prática educativa. São Paulo: Paz 
e Terra, 2003.

4. FREIRE, P. Pedagogia do Oprimido. São Paulo: Paz e Terra, 1996.

5. GADOTTI, Moacir. Pensamento Pedagógico Brasileiro. São Paulo: Atica, 2000.

6. GARCIA, V. A. A educação não formal no âmbito do poder público: avanços e limites. Educação não formal: cenários da criação. Campinas: Unicamp, 2001.

7. GUIDDENS, Anthony. Sociologia. Porto Alegre: Artmed, 2005.

8. GOHN, M. da G. Educação Não-Formal e Cultura Política: impactos sobre o associativismo do terceiro setor. São Paulo: Cortez, 1999.

9. GOHN, M.G. Educação não-formal e cultura política. Campinas: Cortez, 2001.

10. GOHN, M.G. Educação não formal, participação da sociedade civil e estruturas colegiadas nas escolas. Revista Ensaio, Rio de Janeiro, v. 14, n 50, jan/mar, 2006.

11. GRACIANI, M.S.S. Pedagogia social de rua. São Paulo: Cortez, 2006.

12. IMBERNÓN, Francisco. Formação docente e profissional: formar-se para a mudança e a incerteza. 2. ed. São Paulo: Cortês, 2004.

13. LIBANEO, José Carlos. As práticas de organização e de gestão da escola e a formação continuada de professores. In: CONGRESSO INTERNACIONAL DE FORMAÇÃO CONTINUADA E PROFISSIONALIZAÇÃO DOCENTE, 1., 2005, Natal. Anais... Natal: [ s. n. ], 2005. p. 23 - 29.

14. MANTOAN, M.T.E. Compreendendo a deficiência mental: novos caminhos educacionais. São Paulo: Editora Scipione, 1988.

15. McLAREN, Peter. Pedagogia revolucionária na globalização. Rio de Janeiro: DP\&A, 2002.

16. NÓVOA, Antônio; POKEWITZ, Thomas S. Reformas educativas e formação de professores. Lisboa: Educa, 1992.

17. ORTEGA, J. Educación social especializada. Barcelona: Ariel, 1999.

18. PÉREZ -NÚÑEZ, Violeta. El Lugar de La Educación frente a la asignación social de los destinos. In: MOLINA, José García (coord). De novo, la educación social. Madrid: Dykinson, 2003 a. p. 209 a 218.

19. PETRUS, Antoni. Novos Âmbitos em Educação Social. Profissão: Educador Social. Porto Alegre: Artmed, 2003.

20. QUINTANA, J.M. Pedagogia Social. Madrid: Dikynson, 1989.

21. ROMANS, Mercé. Formação Continuada dos Profissionais em Educação Social. Profissão: Educador Social. Porto Alegre: Artmed, 2003.

22. SACRISTÁN, J GIMENO. Tendências investigativas na formação de professores. In: PIMENTA, S.G (org). Professor reflexivo no Brasil: gênese e crítica de um conceito. SP: Cortez, 2002.

23. TARDIF, Maurice. Saberes docentes e formação profissional. Petrópoles: Vozes, 2002.

24. TARDIF, Maurice; LESSARD, C.; GAUTHIER, C. Formation des maitres et contextes sociaux. Paris: Puf, 2000. 